\title{
FARMACOTERAPIA APLICADA À COVID-19
}

\section{ARTIGO DE REVISÃO}

GONÇALVES, Emanuella Dutra ${ }^{1}$

JUSTINIANO, Ana Luisa Marossi ${ }^{2}$

FREITAS, Camila de Carvalho e ${ }^{3}$

ABRAME, Éttore Eduardo Simensato ${ }^{4}$

REINALDI, João Remesso Ferreira ${ }^{5}$

MATOS, Laura Ribeiro de ${ }^{6}$

GONÇALVES, Emanuella Dutra. Et al. Farmacoterapia aplicada à COVID-19. Revista Científica Multidisciplinar Núcleo do Conhecimento. Ano 05, Ed. 10, Vol. 08, pp. 58-81. Outubro de 2020. ISSN: 2448-0959, Link de acesso: https://www.nucleodoconhecimento.com.br/saude/farmacoterapia

${ }^{1}$ Discente do curso de graduação em Medicina da Faculdade de Medicina de Jundiaí (FMJ), Jundiaí, SP, Brasil.

${ }^{2}$ Discente do curso de graduação em Medicina da Faculdade de Medicina de Jundiaí (FMJ), Jundiaí, SP, Brasil.

${ }^{3}$ Discente do curso de graduação em Medicina da Faculdade de Medicina de Jundiaí (FMJ), Jundiaí, SP, Brasil.

${ }^{4}$ Discente do curso de graduação em Medicina da Faculdade de Medicina de Jundiaí (FMJ), Jundiaí, SP, Brasil.

${ }^{5}$ Discente do curso de graduação em Medicina da Faculdade de Medicina de Jundiaí (FMJ), Jundiaí, SP, Brasil.

${ }^{6}$ Discente do curso de graduação em Medicina da Faculdade de Medicina de Jundiaí (FMJ), Jundiaí, SP, Brasil. 


\section{RESUMO}

A epidemia da Doença do Coronavírus (COVID-19) causada pelo vírus SARS-CoV-2 teve início em dezembro de 2019 em Hubei, China, e rapidamente alcançou proporções mundiais, levando a Organização Mundial da Saúde (OMS) a declarar surto pandêmico em março de 2020. Por tratar-se de uma doença potencialmente grave e muito recente, ainda não foram estabelecidos tratamentos baseados em evidências científicas sólidas. Diante disso, o presente artigo consiste em uma revisão narrativa sobre as principais drogas propostas para o tratamento da doença e seus respectivos mecanismos de ação, bem como alguns dos ensaios clínicos já realizados. Para isso, foi feito um levantamento de publicações no banco de dados das bibliotecas eletrônicas Google Scholar, PubMed e BVS, entre maio e agosto de 2020. De modo geral, Cloroquina/Hidroxicloroquina, Azitromicina, Nitazoxanida, Remdesivir, heparinas e dexametasona apresentam resultados satisfatórios no combate a várias infecções virais e sugerem ações semelhantes no SARS-CoV-2, in vitro, porém os resultados dos ensaios clínicos ainda são controversos. Até o momento, a heparina de baixo peso molecular, o Remdevisir e a dexametasona foram aprovados para utilização em situações específicas, a fim de amenizar complicações clínicas. No entanto, mais estudos deverão ser realizados a fim de determinar uma farmacoterapia assertiva.

Palavras-chave: COVID-19, farmacoterapia, SARS-CoV, fármacos.

\section{INTRODUÇÃO}

O SARS-CoV-2 é um RNA vírus do Gênero betacoronavírus ( $\beta$-CoV), portanto pertence à mesma família do SARS-CoV (Severe Acute Respiratory Syndrome, China 2002-2004) e MERS-CoV (Middle East Respiratory Syndrome, 2012) (MALIK, 2020).

Dentre suas características, o vírus possui uma proteína em sua superfície denominada Spike, capaz de infectar a célula hospedeira a partir da ligação com a enzima conversora de angiotensina 2 (ECA2) associada à serina protease transmembranar tipo 2 (TMPRSS2) dessa mesma célula (ALBINI et al., 2020; 
LOKMAN et al., 2020). Além disso, contém um complexo enzimático RNA-polimerase dependente de RNA (RdRp), o qual viabiliza a replicação do genoma viral e sua transcrição (HILLEN et al., 2020).

A infecção pelo SARS-CoV-2 pode levar ao desenvolvimento da doença COVID-19. Várias manifestações clínicas podem ocorrer envolvendo o comprometimento de diversos sistemas, visto que a ECA2 é expressa em diferentes tecidos como pulmões (nos pneumócitos tipo 2), células cardíacas, células do epitélio renal, células endoteliais, epitélio da superfície ocular e enterócitos do intestino delgado (ALBINI et al., 2020; COLLIN et al., 2020; WADMAN et al., 2020).

Os sintomas geralmente começam com síndromes inespecíficas, incluindo febre, tosse seca e fadiga. Também pode ocorrer: falta de ar, dor de garganta, rinorreia, hemoptise e dor no peito (sistema respiratório); diarreia, náusea e vômito (sistema gastrointestinal); dor muscular (sistema músculo-esquelético) e dor de cabeça ou confusão (sistema neurológico) (WU et al., 2020).

A doença pode se expressar com um quadro de comprometimento sistêmico envolvendo a imunidade inata e adaptativa do indivíduo. Os pacientes com quadro grave apresentam um estado de hiperinflamação, mesmo com baixa carga viral. A inflamação sustentada e a formação de infiltrado inflamatório nos pulmões geram edema e lesão da membrana alvéolo-capilar, o que prejudica a hematose e contribui com a hipóxia. Ocorre ainda, o desequilíbrio de linfócitos $T$ ( $T$ helper e $T$ regulator) e a ativação de monócitos por vias inflamatórias intracelulares como a do inflamassoma NLR Family pyrin domain containing 3 (NLRP3); Janus Kinase (JAK); fator nuclear kappa B (NF-Kb). Diante deste quadro, há uma tempestade de citocinas, principalmente interleucina-6 (IL-6); interleucina-2 (IL-2); interleucina-7 (IL-7); fator de necrose tumoral alfa (TNF- $\alpha$ ); interferon gama (IFN-y), bem como a presença de marcadores de lesão miocárdica (AKHMEROV e MARBÁN, 2020; MERAD e MARTIN, 2020; WIERSINGA et al., 2020).

Também foi observado um estado pró-coagulatório nesses pacientes críticos, predispondo eventos trombóticos. O vírus provavelmente se liga ao endotélio vascular 
e 0 ativa. Além disso, a tempestade de citocinas acelera o efeito, principalmente a partir da ação de TNF- $\alpha$ e IL-6 sobre o endotélio, os quais ativam o fator tecidual envolvido com o processo de coagulação (MERAD e MARTIN, 2020; WIERSINGA et al., 2020).

Em 11 de março de 2020, a OMS declarou surto pandêmico de COVID-19 (ORGANIZAÇÃO PAN-AMERICANA DA SAÚDE, 2020). Os dados do Brasil e do mundo referentes à doença, até a data de 31 de agosto, constam na Figura 1 (MINISTÉRIO DA SAÚDE, 2020; WORLD HEALTH ORGANIZATION, 2020). Dessa forma, há urgência em se descobrir uma farmacoterapia assertiva para enfrentar a pandemia e, levando em consideração razões econômicas, o redirecionamento terapêutico de fármacos já aprovados e estudados seria uma opção rápida e viável. Essa estratégia já é amplamente utilizada e auxilia no desenvolvimento de medicações com boa relação custo-benefício e com perfis de segurança já conhecidos (MULLARD, 2011).

Portanto, o presente estudo consiste em uma revisão narrativa que busca demonstrar alguns dos medicamentos utilizados em pesquisas no tratamento da COVID-19, bem como seus mecanismos de ação e principais ensaios clínicos e laboratoriais realizados até o momento. 
Figura 1. Dados epidemiológicos da COVID-19 no Brasil e no mundo.

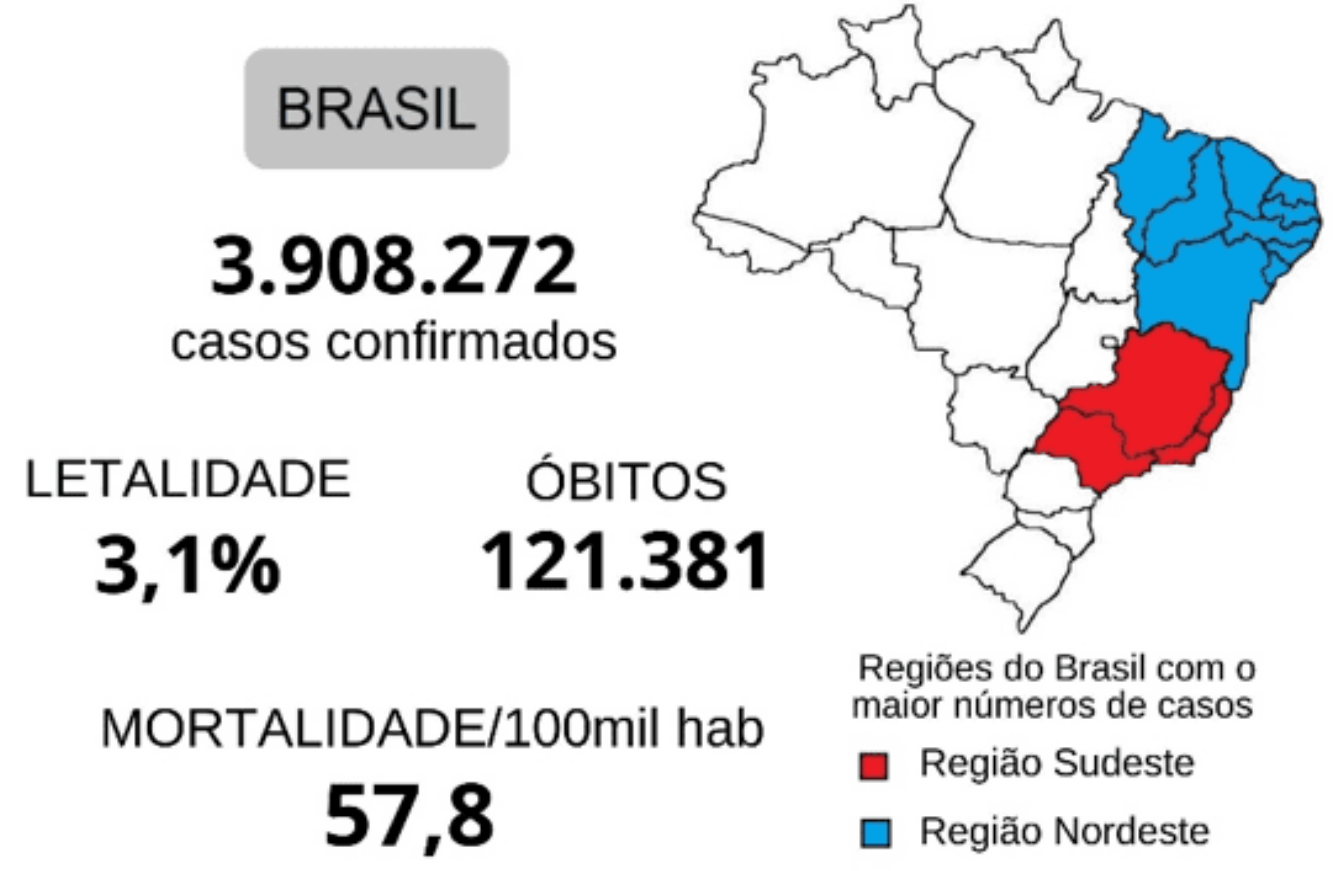

MUNDO

25.118.689

casos confirmados
844.312

óbitos confirmados

Fonte: Os autores, 2020.

\section{DESENVOLVIMENTO}

\subsection{CLOROQUINA E HIDROXICLOROQUINA}

Conhecidos por suas ações antimalárica e antirreumática, a Cloroquina (CQ) e Hidroxicloroquina (HCQ) passaram a ser estudadas como possíveis drogas promissoras diante do atual cenário de pandemia pela COVID-19. Uma revisão publicada em Marseille, França, Didier Raoult et al. (2007) mostram que, nos últimos 13 anos, esses medicamentos já vinham sendo investigados por atuarem 
intracelularmente em infecções causadas por diferentes fungos, bactérias e vírus, inclusive HIV e SARS-CoV-1.

De modo geral, os mecanismos de ação propostos podem ser divididos em quatro etapas. A primeira delas se refere à inibição da ativação dos linfócitos $T$ e, consequentemente, diminuição da produção de citocinas inflamatórias. Esse processo se inicia a partir da concentração destes fármacos em organelas citoplasmáticas, causando aumento do $\mathrm{pH}$ fisiológico. Sem o funcionamento correto dos lisossomos, os peptídeos virais deixam de ser produzidos dentro das células apresentadoras de antígenos (APCs), impedindo a ligação entre peptídeo viral e complexo principal de histocompatibilidade (MHC) classe II, o qual deixa de ser expresso na superfície celular. Ao impedir o processamento de antígenos e sua apresentação aos linfócitos auxiliares ( $T \mathrm{CD} 4+)$, ocorre queda dessas células com consequente redução de citocinas produzidas por linfócitos T e B (IL-1, IL-6, TNF) (ZHOU et al., 2020).

A segunda etapa consiste na interrupção da interação entre ligantes virais e receptores toll-like (TLR7 e TLR9), localizados na superfície de células pertencentes ao sistema imunológico inato. Além disso, no citoplasma, esses fármacos são capazes de interferir no funcionamento do sensor de ácido nucléico "GMP-AMP cíclico-sintase" (cGAS) dessas células. Dessa forma, tanto a sinalização superficial (TRL) quanto a estimulação do cGAS são suprimidas, atenuando a ativação de sinais próinflamatórios e a produção de citocinas (ZHOU et al., 2020).

A terceira e quarta etapas envolvem a entrada e replicação do vírus. Na pré-infecção a $\mathrm{CQ}$ e $\mathrm{HCQ}$ interferem na glicosilação da ECA2 que, com seu funcionamento alterado, impede a ligação com os peptídeos das proteínas virais e, portanto, a fusão não ocorre. Há ainda, o funcionamento inadequado dos endossomos e lisossomos em virtude da alteração do $\mathrm{pH}$ celular, como já mencionado. O vírus deixa de se fundir ao endossomo, etapa essencial para sua replicação e, além disso, os lisossomos perdem a capacidade de produzir as enzimas proteases responsáveis pela clivagem das proteínas virais Spike, impedindo a liberação e ligação de peptídeos na ECA2, bloqueando, mais uma vez, a infecção viral (ZHOU et al., 2020). 
Dos primeiros estudos relacionados à infecção pelo SARS-CoV-2, destacam-se Wang M. et al. (2020), Liu et al. (2020) e Yao et al. (2020), os quais analisaram células in vitro com resultados favoráveis (Tabela 1). No entanto, o risco de viés é alto, visto que não se sabe o comportamento em humanos quando extensivamente testado.

Tabela 1. Estudos in vitro da Cloroquina e Hidroxicloroquina na COVID-19.

\begin{tabular}{|c|c|c|c|c|}
\hline Autor/ano & $\begin{array}{l}\text { Desenho } \\
\text { de } \\
\text { estudo }\end{array}$ & População & Objetivos & Resultados \\
\hline $\begin{array}{l}\text { Wang M. } \\
\text { et al., } \\
2020\end{array}$ & $\begin{array}{l}\text { Estudo in } \\
\text { vitro }\end{array}$ & NA & $\begin{array}{l}\text { Avaliar o efeito da } \\
\mathrm{CQ} \text { in vitro usando } \\
\text { células Vero E6 } \\
\text { infectadas (células } \\
\text { do rim do macaco } \\
\text { verde africano). }\end{array}$ & $\begin{array}{l}\text { Possível efeito } \\
\text { bloqueador da infecção } \\
\text { viral com atuação na pré } \\
\text { e pós-infecção. Foi } \\
\text { relatadarande } \\
\text { seletividade contra o } \\
\text { vírus, sem } \\
\text { comprometimento das } \\
\text { células hospedeiras. }\end{array}$ \\
\hline $\begin{array}{l}\text { Liu et al., } \\
2020\end{array}$ & $\begin{array}{l}\text { Estudo in } \\
\text { vitro }\end{array}$ & NA & $\begin{array}{l}\text { Avaliar a atividade } \\
\text { antiviral da CQ } \\
\text { versus } \mathrm{HCQ} \text { in } \\
\text { vitro, além das } \\
\text { curvas dose- } \\
\text { resposta dos dois } \\
\text { compostos. }\end{array}$ & $\begin{array}{l}\text { A CE50 para CQ foi } \\
\text { menor que o do HCQ. } \\
\text { Portanto, a CQ mostrou } \\
\text { ser mais potente contra a } \\
\text { infecção viral. }\end{array}$ \\
\hline $\begin{array}{l}\text { Yao et al., } \\
2020\end{array}$ & $\begin{array}{l}\text { Estudo in } \\
\text { vitro }\end{array}$ & NA & $\begin{array}{l}\text { Analisar } \\
\text { atividade } \\
\text { farmacológica da } \\
\mathrm{CQ} \text { e HCQ em } \\
\text { células Vero } \\
\text { infectadas. }\end{array}$ & $\begin{array}{l}\text { A HCQ }(\text { CE50 }=0,72 \mu \mathrm{M}) \\
\text { é mais potente que a } \\
\text { cloroquina }(\text { CE50 }=5,47 \\
\mu \mathrm{M}) .\end{array}$ \\
\hline
\end{tabular}


Abreviaturas: CE50, concentração efetiva máxima de 50\%; $C Q$, Cloroquina; $\mathrm{HCQ}$, Hidroxicloroquina; NA, não aplicável.

Fonte: Os autores, 2020.

$\mathrm{Na}$ Tabela 2 estão mencionados alguns estudos in vivo, como os de Gao et al. (2020), Chen J. et al. (2020) e Gautret et al. (2020). Contudo, esses dois últimos trabalhos deixam de ter fundamentos confiáveis, pois apresentam diversas limitações metodológicas (pequenas amostras, ausência de acompanhamento a longo prazo e medidas indiretas da presença viral) (DUMAS-MALLET et al., 2017). Além disso, o estudo de Gautret et al. (2020) consiste em um ensaio clínico aberto, não randomizado, onde houve abandono de seis pacientes durante a pesquisa (RANGANATHAN et al., 2016).

Já no estudo apresentado por Chen Z. et al. (2020) (Tabela 2), o viés de medição indireta da presença viral deixa de existir, pois a análise passou a ser em relação à clínica do paciente. Outros desfechos relevantes foram avaliados por Magagnoli et al. (2020) (Tabela 2), porém trata-se de um estudo retrospectivo, com baixa qualidade metodológica, resultando em perda de confiabilidade (DUMAS-MALLET et al., 2017).

Pesquisas como as de Mathian et al. (2020), Tang et al. (2020) e Mahévas et al. (2020) tentaram associar a atividade dos medicamentos em populações específicas, mostrando resultados contraditórios até o momento, como também pode ser visto na Tabela 2.

Portanto, apesar dos primeiros estudos in vivo mostrarem benefícios do uso da HCQ na infecção pelo SARS-CoV-2, pesquisas mais recentes mostram resultados opostos. Além disso, todos os estudos apresentados nesta revisão possuem algum tipo de limitação metodológica, o que impossibilita evidências confiáveis para o uso desses medicamentos na COVID-19. 
Tabela 2. Estudos in vivo da Cloroquina e Hidroxicloroquina na COVID-19.

\begin{tabular}{|c|c|c|c|c|}
\hline Autor/ano & $\begin{array}{l}\text { Desenho de } \\
\text { estudo }\end{array}$ & População & Objetivos & Resultados \\
\hline $\begin{array}{l}\text { Gao et al., } \\
2020\end{array}$ & $\begin{array}{l}\text { Carta } \\
\text { narrativa de } \\
\text { ensaios } \\
\text { clínicos } \\
\text { randomizado } \\
\text { s }\end{array}$ & $\begin{array}{l}\text { Mais de } 100 \\
\text { participantes. }\end{array}$ & $\begin{array}{lr}\text { Analisar o uso de } \\
\text { fosfato } & \text { de } \\
\text { cloroquina } & \text { em } \\
\text { mais de } & 100 \\
\text { pacientes. } & \end{array}$ & $\begin{array}{l}\text { Houve melhora } \\
\text { nos quadros de } \\
\text { pneumonia, } \\
\text { exames de } \\
\text { imagem } \\
\text { pulmonar e } \\
\text { desenvolviment } \\
\text { o da doença, } \\
\text { sem que } \\
\text { houvesse } \\
\text { efeitos adversos } \\
\text { graves. }\end{array}$ \\
\hline $\begin{array}{l}\text { Chen J. et } \\
\text { al., } 2020\end{array}$ & $\begin{array}{l}\text { Ensaio clínico } \\
\text { randomizado } \\
\text { aberto }\end{array}$ & $\begin{array}{l}30 \text { pacientes } \\
\text { confirmados } \\
\text { com COVID- } \\
19 .\end{array}$ & $\begin{array}{l}\text { Analisar o uso da } \\
\mathrm{HCQ} \text { como } \\
\text { tratamento, } \\
\text { comparativament } \\
\text { e ao grupo } \\
\text { controle. }\end{array}$ & $\begin{array}{l}\text { Não foram } \\
\text { obtidas } \\
\text { diferenças } \\
\text { significativas } \\
\text { entre os grupos } \\
\text { em relação à } \\
\text { duração da } \\
\text { doença e à } \\
\text { carga viral após } \\
\text { exame de RT- } \\
\text { PCR em células } \\
\text { de nasofaringe } \\
\text { no sétimo dia de } \\
\text { estudo. }\end{array}$ \\
\hline
\end{tabular}




\begin{tabular}{|c|c|c|c|c|}
\hline $\begin{array}{l}\text { Gautret et } \\
\text { al., } 2020\end{array}$ & $\begin{array}{l}\text { Ensaio clínico } \\
\text { não } \\
\text { randomizado }\end{array}$ & $\begin{array}{l}36 \text { pacientes: } \\
16 \text { do grupo } \\
\text { controle, } 20 \text { do } \\
\text { grupo tratado } \\
\text { com HCQ. }\end{array}$ & $\begin{array}{l}\text { Relacionar o uso } \\
\text { da } \mathrm{HCQ} \text { isolada, e } \\
\text { com associação à } \\
\text { AZM, com } \\
\text { aqueles em que } \\
\text { não receberam } \\
\text { um tratamento } \\
\text { específico. }\end{array}$ & 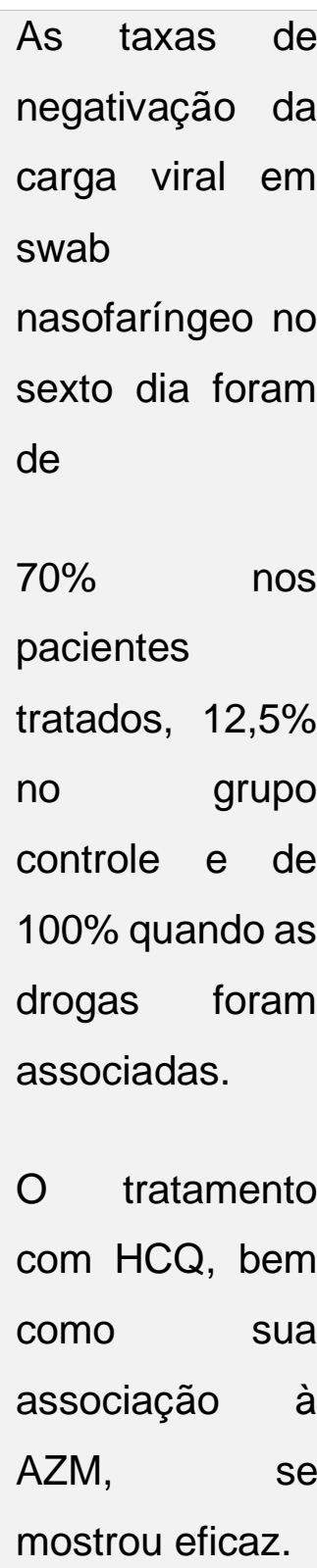 \\
\hline $\begin{array}{l}\text { Chen Z. et } \\
\text { al., } 2020\end{array}$ & $\begin{array}{l}\text { Ensaio clínico } \\
\text { randomizado } \\
\text { aberto }\end{array}$ & $\begin{array}{l}62 \text { pacientes } \\
\text { com sintomas } \\
\text { leves } \\
\text { separados em } \\
\text { grupo controle } \\
\text { e grupo } \\
\text { experimental } \\
\text { (introdução da } \\
\text { HCQ). }\end{array}$ & $\begin{array}{l}\text { Analisar o uso da } \\
\text { HCQ com base na } \\
\text { clínica do } \\
\text { paciente. }\end{array}$ & $\begin{array}{l}\text { O tempo médio } \\
\text { para } \\
\text { recuperação } \\
\text { clínica } \\
\text { (resolução de } \\
\text { febre, tosse e } \\
\text { melhora na } \\
\text { radiografia } \\
\text { torácica) foi }\end{array}$ \\
\hline
\end{tabular}




\begin{tabular}{|c|c|c|c|c|}
\hline & & & & $\begin{array}{l}\text { menor no grupo } \\
\text { experimental. } \\
\text { Houve piora } \\
\text { clínica em } \\
\text { quatro pacientes } \\
\text { do grupo } \\
\text { controle. }\end{array}$ \\
\hline $\begin{array}{l}\text { Magagnol } \\
\text { i et al., } \\
2020\end{array}$ & $\begin{array}{l}\text { Estudo } \\
\text { observacional } \\
\text { de coorte } \\
\text { histórico }\end{array}$ & $\begin{array}{l}368 \text { pacientes } \\
\text { de diferentes } \\
\text { centros } \\
\text { médicos da } \\
\text { Veterans } \\
\text { Health } \\
\text { Administration. }\end{array}$ & $\begin{array}{l}\text { Relacionar o uso } \\
\text { da HCQ, } \\
\text { associada ou não } \\
\text { a com AZM, com } \\
\text { a mortalidade e } \\
\text { necessidade de } \\
\text { ventilação } \\
\text { mecânica. }\end{array}$ & $\begin{array}{l}\text { Não há } \\
\text { evidências de } \\
\text { que o uso de } \\
\text { HCQ, com ou } \\
\text { sem AZM, reduz } \\
\text { o risco de } \\
\text { ventilação } \\
\text { mecânica, ao } \\
\text { passo } \\
\text { pacientes } \\
\text { expostos } \\
\text { tratamento ao } \\
\text { padrão possuem } \\
\text { menor risco de } \\
\text { morte. }\end{array}$ \\
\hline $\begin{array}{l}\text { Mathian } \\
\text { et al., } \\
2020\end{array}$ & $\begin{array}{l}\text { Estudo } \\
\text { observacional } \\
\text { de casos }\end{array}$ & $\begin{array}{l}17 \text { pacientes } \\
\text { diagnosticados } \\
\text { com Lúpus } \\
\text { Eritematoso } \\
\text { Sistêmico em } \\
\text { uso crônico de } \\
\text { HCQ. }\end{array}$ & 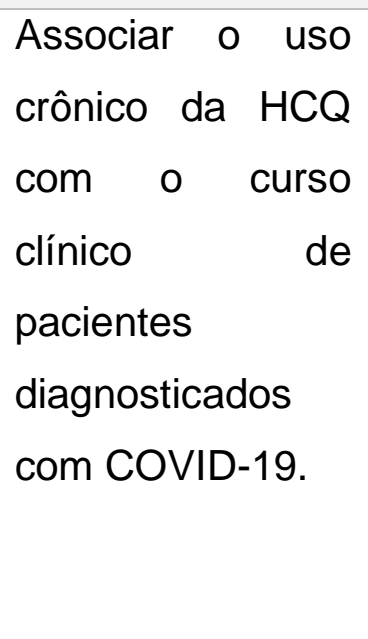 & $\begin{array}{l}\text { Mesmo quando } \\
\text { usada em doses } \\
\text { terapêuticas por } \\
\text { tempo } \\
\text { prolongado, a } \\
\text { HCQ não foi } \\
\text { capaz a } \\
\text { impedir a } \\
\text { infecção ou as }\end{array}$ \\
\hline
\end{tabular}




\begin{tabular}{|c|c|c|c|c|}
\hline & & & & $\begin{array}{l}\text { complicações da } \\
\text { COVID-19. }\end{array}$ \\
\hline $\begin{array}{l}\text { Tang et } \\
\text { al., } 2020\end{array}$ & $\begin{array}{l}\text { Estudo } \\
\text { observacional } \\
\text { de caso- } \\
\text { controle }\end{array}$ & $\begin{array}{l}150 \text { pacientes } \\
\text { com quadros } \\
\text { clínicos leves e } \\
\text { moderados de } \\
\text { COVID-19. }\end{array}$ & $\begin{array}{l}\text { Relacionar o uso } \\
\text { da HCQ com } \\
\text { casos leves e } \\
\text { moderados da } \\
\text { COVID-19. }\end{array}$ & $\begin{array}{l}\text { Não foi } \\
\text { observado } \\
\text { benefício no uso } \\
\text { do medicamento } \\
\text { na negativação } \\
\text { viral. Além } \\
\text { disso, de } \\
\text { ocorrência do } \\
\text { efeitos adversos } \\
\text { foi maior no } \\
\text { grupo que } \\
\text { utilizou a droga. }\end{array}$ \\
\hline $\begin{array}{l}\text { Mahévas } \\
\text { et al., } \\
2020\end{array}$ & $\begin{array}{l}\text { Estudo } \\
\text { observacional } \\
\text { de caso- } \\
\text { controle }\end{array}$ & $\begin{array}{l}181 \text { pacientes } \\
\text { com COVID-19 } \\
\text { em uso de } \\
\text { oxigenoterapia } \\
\text { mas sem } \\
\text { necessidade } \\
\text { de cuidados } \\
\text { intensivos. }\end{array}$ & $\begin{array}{l}\text { Relacionar o uso } \\
\text { da HCQ com } \\
\text { casos severos da } \\
\text { COVID-19. }\end{array}$ & $\begin{array}{l}\text { As taxas de } \\
\text { sobrevivência } \\
\text { sem UTI foram } \\
\text { semelhantes } \\
\text { entre o grupo } \\
\text { controle e o } \\
\text { grupo que } \\
\text { recebeu a } \mathrm{HCQ} \text {. }\end{array}$ \\
\hline
\end{tabular}

Abreviaturas: AZM, Azitromicina; HCQ, Hidroxicloroquina; RT-PCR, Reação em cadeia da polimerase via transcriptase reversa.

Fonte: Os autores, 2020.

\subsection{AZITROMICINA}

O uso da Azitromicina (AZM) na COVID-19 surgiu a partir dos benefícios já vistos in vivo e in vitro em outras infecções virais, como Zika vírus, Ebola vírus, rinovírus e na prevenção de infecções virais graves do trato respiratório (AL-HASAN e AL- 
JAGHBEER, 2020; BOUSSEBOUEF et al., 2018; MENZEL et al., 2016; SUN et al., 2017). A AZM no tratamento dessas doenças é responsável pelo aumento dos genes produtores de IFNs e redução da entrada, replicação e liberação do vírus pela célula, tendo como consequência menor proliferação viral.

Até o momento, nenhum mecanismo de ação foi encontrado para AZM na COVID-19, porém sabe-se que esta age em sinergismo à $\mathrm{HCQ}$, justificando a realização de pesquisas que buscaram analisar a associação dessas duas drogas, como no estudo francês de Gautret et al. (2020).

Com isso, outras pesquisas foram publicadas na mesma linha de raciocínio. Um estudo francês não randomizado, também do autor Gautret et al. (2020), envolveu 80 pacientes e o método de análise utilizado foi a cultura e a reação em cadeia da polimerase via transcriptase reversa (RT-PCR) da nasofaringe, os quais negativaram em menor tempo quando comparado com o grupo que não utilizou a terapia combinada de HCQ e AZM, concluindo que a associação reduzia o tempo de contagiosidade do vírus. Por outro lado, a pesquisa realizada por Chorin et al. (2020) acompanhou 251 pacientes os quais realizaram eletrocardiograma durante três dias a fim de determinar a prevalência de arritmias, bem como a mortalidade associada. Conclui-se que o uso em conjunto dos fármacos prolonga o segmento QT em uma proporção significativa dos pacientes e, portanto, aumenta o risco de torsade de pointes $(T d P)$.

Ainda há poucos estudos sobre o tema e pouco se conhece sobre a ação desse medicamento na COVID-19. Porém, o uso da AZM tem-se mostrado promissor desde que sejam tomadas medidas preventivas para possíveis efeitos colaterais.

\subsection{NITAZOXANIDA}

Descoberta em meados da década de 1980, a Nitazoxanida (NTZ) foi aprovada como um medicamento antiprotozoário e passou a ser utilizada em infecções por Cryptosporidium e Giardia (GRUPTA et al., 2006). Tempo depois, verificou-se a 
capacidade antiviral contra hepatite B e C em pacientes co-infectados pelo HIV (KORBA et al., 2008).

A partir de então, diversos estudos in vitro com outras doenças infecciosas foram realizados, demonstrando uma boa eficácia contra os vírus influenza, rotavírus, norovírus, astrovírus, vírus da encefalite japonesa (JEV), rubéola, Zika vírus, hepatite B, hepatite C e coronavírus (ROSSIGNOL, 2014; TOTURA e BAVARI, 2019). Além disso, Wang M. et al. (2020) contribuíram para demonstrar uma significativa atividade da NTZ como inibidora do SARS-CoV-2 em baixas concentrações micromolares in vitro.

A produção de IFN faz parte dos principais mecanismos protetores celulares durante uma infecção viral. Dentre vários outros mecanismos de evasão do sistema imune, o novo coronavírus é capaz de influenciar negativamente na via de IFN por meio de suas proteínas como, por exemplo, a nonstructural protein 15 (nsp15) (FRIEMAN e BARIC, 2008). Isso pode ser comprovado pelo estudo de Deng et al. (2017), a partir da inoculação de vírus mutante com nps 15 alterada em camundongos experimentais, mostrando que $100 \%$ da amostra que recebeu a dose letal do vírus mutante conseguiu sobreviver, ao passo que $100 \%$ dos que receberam a mesma dose sem alteração genética não resistiu até o final da pesquisa. Com isso, ficou clara a participação da evasão imune inata na patogenicidade da COVID-19.

Jasenosky et al. (2019) demonstraram que a NTZ aumentou de forma significativa os níveis de sensores, proteínas e efetores intracelulares, entre os quais genes estimulados por IFN com repostas antivirais. A capacidade do fármaco em amplificar moléculas participantes da via do IFN configura seu principal mecanismo de ação nessa doença, permitindo a célula restabelecer suas atividades antivirais ao bloquear o mecanismo de evasão imunológica.

Nos últimos meses, observou-se que pacientes idosos possuem uma maior morbimortalidade provocada pela COVID-19 e, de fato, ao longo dos anos, os indivíduos vão perdendo sua capacidade imunológica inata, fenômeno denominado "senescência imune" (BAAS et al., 2008; FRIEMAN e BARIC, 2008; FRIEMAN et al., 
2007). Assim, a NTZ torna-se uma grande promessa na redução dos danos causados pela doença, mesmo nessa população, por ser capaz de resgatar os componentes da via de sinalização do IFN.

Embora se apresente como uma boa candidata terapêutica contra a COVID-19, estudos in vivo foram negligenciados até o momento, sendo necessário, portanto, ensaios clínicos urgentes para testagem, de fato, da eficácia do medicamento.

\subsection{REMDESIVIR}

O Remdesivir foi produzido para ser utilizado como uma possível abordagem contra o vírus Ebola, porém mostrou eficácia somente em estudos in vitro. Mais recentemente, apresentou atividades antivirais contra o SARS-CoV-2, configurando como uma das terapias mais promissoras para o enfrentamento da COVID-19 (SIEGEL et al., 2017).

O Remdesivir é administrado por via intravenosa e seu mecanismo de ação proposto envolve o bloqueio da atividade da RdRp, ou seja, a interrupção da produção da cadeia de RNA viral. Trata-se de um pró-fármaco análogo de nucleotídeos que, no meio intracelular, forma um metabólito (GS-443902), o qual compete com o nucleotídeo proveniente da célula hospedeira, bloqueando, dessa forma, o alongamento da cadeia de RNA viral a partir da RdRp (HILLEN et al., 2020; JORGENSEN et al., 2020; SIEGEL et al., 2017, US FOOD AND DRUG ADMINISTRATION, 2020).

Wang Y et al. (2020) realizaram um ensaio clínico em dez hospitais em Hubei, China. Dos 237 pacientes randomizados, 158 receberam o Remdesivir e 79, o placebo. O desfecho primário foi a apresentação de melhora clínica em até 28 dias, ou a alta hospitalar. Não foi observada redução estatisticamente significante do tempo de melhora clínica (em média 21 dias com o uso do Remdesivir contra 23 dias para o grupo placebo; razão de risco de morte 1.23 [Intervalo de Confiança (IC) 95\%, 0.87 $1.75])$. 
Goldman et al. (2020) conduziram um estudo aberto, fase III em 55 hospitais (Estados Unidos da América, Europa e Ásia) comparando o uso do Remdesivir por cinco ou dez dias. Foram randomizados 397 pacientes, dos quais 200 receberam o tratamento por cinco dias e 197 por dez dias. No 14ํ dia houve uma melhora clínica semelhante entre os grupos (64\% dos pacientes no grupo de cinco dias e $54 \%$ no grupo de dez dias). Apesar de o ensaio clínico ser aberto e da maioria do grupo de dez dias ter descontinuado o tratamento (56\%), pode-se inferir que não há diferença significativa em relação ao tempo de uso do Remdesivir.

Adultos hospitalizados e com evidências de comprometimento do trato respiratório inferior pela COVID-19 foram analisados quanto ao tempo de recuperação no estudo de Beigel et al. (2020). Participaram 1063 pacientes que, após serem randomizados, 538 receberam o Remdesivir e 521 o placebo por até dez dias. Embora o Remdesivir não tenha apresentado uma significância estatística quanto à diminuição da mortalidade em 14 dias (7.1\% com Remdesivir e 11.9\% no grupo placebo, com razão de risco de morte 0.70 [IC 95\%, 0.47 - 1.04]), houve uma melhora no tempo de recuperação: 11 dias para aqueles que receberam o medicamento (IC 95\%, 9 - 12), e 15 dias para os que receberam placebo (IC 95\%, 13 - 19), apresentando menor tempo de recuperação com risco relativo (RR) de 1.32 (IC 95\%, 1.12 - 1.55).

Até o momento, ensaios clínicos randomizados, duplos-cegos e placebo-controlados não forneceram evidências que aconselhe o uso dessa droga. Entretanto, considerando a potencial ameaça de vida da manifestação severa da COVID-19 e a falta de terapias específicas, a US Food and Drug Administration (FDA) aprovou o uso emergencial do Remdesivir para pacientes hospitalizados e em situação grave (ISON et al., 2020; US FOOD AND DRUG ADMINISTRATION, 2020).

\subsection{ANTICOAGULANTES}

As heparinas não fracionadas (HNF) e de baixo peso molecular (HBPM) possuem três ações na infecção pelo novo coronavírus: anticoagulante, antiviral e anti-inflamatória. $O$ efeito anticoagulante é o de maior conhecimento pela comunidade científica. Tang et al. (2020) realizaram um estudo retrospectivo concluindo que sete dias de terapia 
anticoagulante (principalmente $\mathrm{HBPM}$ ) se relaciona à menor mortalidade dos pacientes com sepse induzida por coagulopatia.

A alteração dos parâmetros da coagulação sanguínea sugere pior prognóstico na COVID-19, especialmente a elevação do produto de degradação fibrinolítica e de dímero $D$, o aumento do tempo de protrombina e a redução na contagem de plaquetas (ARACHCHILLAGE e LAFFAN, 2020). Zhang et al. (2020) demonstraram que valores superiores a $2.0 \mu \mathrm{g} / \mathrm{mL}$ de dímero $\mathrm{D}$ (aumento de quatro vezes em relação ao valor de referência), na admissão de pacientes infectados pelo SARS-CoV-2, poderia prever efetivamente a mortalidade, indicando esse parâmetro como um possível marcador precoce que auxiliaria no tratamento da doença.

Quanto à contagem de plaquetas, dois estudos chineses evidenciaram a sua redução. Enquanto Chen N. et al. (2020) mostraram que 12\% dos 1476 pacientes com COVID19 apresentaram plaquetopenia, Guan et al. (2020) obtiveram 36,2\% dos pacientes com valor de plaquetas inferior a $150 \times 10^{9} / \mathrm{L}$. Por fim, o estudo de Yang et al. (2020) constatou aumento da mortalidade conforme reduzia o número de plaquetas.

A COVID-19 por si só é capaz de causar grande liberação de citocinas na circulação sanguínea levando à ativação da cascata de coagulação (CONNORS e LEVY, 2020; ZHANG et al., 2020). Negri et al. (2020) notaram que, em um dos primeiros pacientes infectados pela COVID-19, houve deterioração da função respiratória e isquemia periférica, levando à hipótese de que a insuficiência respiratória seria devido a obstrução capilar pulmonar e a coagulação intravascular disseminada (CIVD). Portanto, considerou-se benéfico o uso de heparina nesses pacientes, inclusive quando utilizada precocemente.

As heparinas também possuem propriedades antivirais sub-exploradas como a atuação em outros vírus da família Coronaviridae (como o SARS-CoV), Flaviviridae, Herpesviridae, além de influenza e HIV (GHEZZI et al., 2017; HARROP e RIDER, 1998; RUSNATI et al., 1997; SKIDMORE et al., 2015; VICENZI et al., 2004; WUDUNN e SPEAR, 1989). Segundo Mycroft-West et al. (2020), esse anticoagulante de ação direta possui sítios de ligação à proteína Spike do SARS-CoV-2 (a qual se liga às 
células do hospedeiro), e a altera, diminuindo a infecção viral. O estudo comprovou a eficiência da heparina (especialmente a HNF), como inibidora das infecções em 70\% de cultura de células Vero in vitro. Também apontou a importância do uso de heparinas complexas as quais, devido à maior sulfatação, possuem estruturas maiores e com mais sítios de ligação, fato comprovado pelo maior efeito inibitório da HNF em relação à HBPM. Ainda não foram publicados estudos in vivo de grande impacto que comprovem o efeito antiviral da heparina contra o SARS-CoV-2.

Por fim, o estudo de Shi et al. (2020), comprova o efeito anti-inflamatório das HBPM. Participaram 42 pacientes divididos em dois grupos de mesmo tamanho, sendo o primeiro submetido ao tratamento com HBPM e o segundo constituindo o controle. Quando comparados, os pacientes do grupo tratado com heparina tiveram aumento significativo do número de linfócitos e plaquetas, além da redução de leucócitos, IL-6 e IL-4. O aumento de linfócitos pode ser decorrente tanto da redução da concentração de IL-6, capaz de causar linfopenia, quanto da redução da infecção viral promovida pela heparina, o que impede uma destruição direta de linfócitos pelo vírus (LIAO et al., 2002). Já o aumento de plaquetas, ocorre pela redução do estado de hipercoagulabilidade. A redução dos leucócitos ocorre à custa da diminuição de fagócitos, devido à queda das interleucinas inflamatórias (IL-6, IL-4). Além disso, houve aumento de TNF- $\alpha$ ao longo do tempo no grupo controle, indicando maior quadro inflamatório nesses pacientes, fato não observado em quem usou a droga (SHI et al., 2020).

\subsection{DEXAMETASONA}

Sabe-se que o desenvolvimento da COVID-19 pode levar o paciente a um quadro grave em decorrência, principalmente, de um estado hiperinflamatório (AKHMEROV e MARBÁN, 2020; CHEN J. et al., 2019; MERAD e MARTIN, 2020). Diante disso, pensou-se que o uso de corticóides como imunomoduladores poderia trazer benefícios.

A dexametasona é um corticóide de longa ação e, além do efeito anti-inflamatório, é utilizada em pneumonias virais graves como a causada pelo vírus influenza (HORBY 
et al., 2020). Partindo desse pressuposto, o Grupo RECOVERY realizou um ensaio clínico randomizado, controlado e aberto, para analisar e comparar o uso desse corticóide com a mortalidade de COVID-19 dentro de 28 dias. Os pacientes foram divididos em dois grupos, de modo que 2104 receberam a dexametasona (6 mg por até dez dias), enquanto 4321 foram submetidos ao tratamento padrão. Segundo o relatório preliminar não houve benefício evidente aos pacientes que não precisaram de suporte respiratório; RR 1.19 (IC 95\%, 0.91 - 1.55), mas, por outro lado, foi benéfico tanto para os pacientes que necessitaram de oxigênio sem ventilação invasiva; RR 0.82 (IC 95\%, 0.72 - 0.94), quanto para os que utilizaram ventilação mecânica invasiva; RR 0.64 (IC 95\%, 0.51 - 0.81). Também foi observado um menor risco de progressão para ventilação mecânica; RR 0.72 (IC 95\%, 0.62 - 0.95) (HORBY et al., 2020).

Além disso, foi constatado melhor efeito da droga em quem apresentou mais de sete dias de sintomas, justificando a sua utilização em pacientes mais graves e com maior tempo de evolução. Isso pode ser explicado pois, em fases mais tardias, os pacientes ainda podem apresentar um estado de intensa inflamação, mesmo com baixa carga viral (AKHMEROV e MARBÁN, 2020). Por outro lado, o uso se mostrou prejudicial quando administrado em fases mais iniciais, por permitir maior replicação viral (HORBY et al., 2020).

Até o momento a dexametasona é o único medicamento que mostrou melhora estatisticamente relevante na taxa de mortalidade dos pacientes com COVID-19. Trata-se de uma droga de baixo custo e acessível à grande parte da população. Portanto, o uso desse fármaco em ambiente hospitalar deve ser incentivado quando necessário.

\section{CONSIDERAÇÕES FINAIS}

De modo geral, os medicamentos mencionados apresentam grande potencial no tratamento da COVID-19 e de suas complicações quando analisados na teoria. Muitos deles possuem resultados satisfatórios no combate a outras infecções virais e se mostram fisiologicamente eficazes através de seus mecanismos de ação. De fato, 
diversas pesquisas in vitro mostraram benefícios em células infectadas pelo SARSCoV-2, apesar de não se adequarem como estudos ideais. Ensaios clínicos posteriores revelam eficácia na utilização de determinados fármacos em certas populações, porém a maioria contém limitações metodológicas que comprometem a confiabilidade.

Até o momento, nenhum medicamento se enquadra como escolha no tratamento da doença. Apesar disso, alguns deles foram aprovados para utilização em situações específicas, como no caso do Remdesivir em indivíduos hospitalizados e em estado grave, da HBPM na profilaxia de tromboembolismo venoso, além da dexametasona, que tem se mostrado como grande promessa em pacientes com maior tempo de evolução da doença. No entanto, é necessário que mais estudos sejam realizados com o objetivo de alcançar a farmacoterapia assertiva.

\section{REFERÊNCIAS}

AKHMEROV A.; MARBÁN E. COVID-19 and the Heart. Circ Res [Internet]. 2020 May 8;126(10):1443-55. doi: 10.1161/CIRCRESAHA.120.317055

ALBINI A.; DI GUARDO G.; NOONAN D.M.; LOMBARDO M. The SARS-CoV-2 receptor, ACE-2, is expressed on many different cell types: implications for ACEinhibitor- and angiotensin II receptor blocker-based cardiovascular therapies. Intern Emerg Med [Internet]. 2020 May 19;(0123456789). Available from: http://www.ncbi.nlm.nih.gov/pubmed/32430651. doi: 10.1007/s11739-020-02364-6

AL-HASAN M.N.; AL-JAGHBEER M.J. Use of Antibiotics in Chronic Obstructive Pulmonary Disease: What is Their Current Role in Older Patients? [published online ahead of print, 2020 Jul 20]. Drugs Aging. 2020;10.1007/s40266-020-00786-7. doi: 10.1007/s40266-020-00786-7

ARACHCHILLAGE D.R.J.; LAFFAN M. Abnormal coagulation parameters are associated with poor prognosis in patients with novel coronavirus pneumonia. $\boldsymbol{J}$ ThrombHaemost. 2020;18(5):1233-1234. doi: 10.1111/jth.14820 
BAAS T.; ROBERTS A.; TEAL T.H.; VOGEL L.; CHEN J.; TUMPEY T.M.; et al. Genomic Analysis Reveals Age-Dependent Innate Immune Responses to Severe Acute Respiratory Syndrome Coronavirus. J Virol. 2008;82(19):9465-76. doi: 10.1128/JVI.00489-08

BEIGEL J.H.; TOMASHEK K.M.; DODD L.E.; MEHTA A.K.; ZINGMAN B.S.; KALIL A.C.; et al. Remdesivir for the Treatment of Covid-19 - Preliminary Report. N Engl J Med [Internet]. 2020 May 22;NEJMoa2007764. Available from: http://www.ncbi.nlm.nih.gov/pubmed/32445440. doi: 10.1056/NEJMoa2007764

BOUSSEBOUEF E.; AUBRY M.; NHAN T.X.; PINA J.J.; ROLAIN J.M.; RAOULT D.; et al. Azithromycin Inhibits the Replication of Zika Virus. Jornal of antivirals and antiretrovirals. 2018. doi: 10.4172/1948-5964.1000173

CHEN J.; LIU D.; LIU L.; LIU P.; XU Q.; XIA L.; et al. A pilot study of hydroxychloroquine in treatment of patients with moderate COVID-19. J Zhejiang Univ Medical Sci. 2019;49(2):215-9. doi: 10.3785/j.issn.1008-9292.2020.03.03

CHEN N.; ZHOU M.; DONG X.; QU J.; GONG F.; HAN Y.; et al. Epidemiological and clinical characteristics of 99 cases of 2019 novel coronavirus pneumonia in Wuhan, China: a descriptive study. Lancet. 2020;395(10223):507-513. doi: 10.1016/S01406736(20)30211-7

CHEN Z.; HU J.; ZHANG Z.; JIANG S.; HAN S.; YAN D.; et al. Efficacy of hydroxychloroquine in patients with COVID-19: results of a randomized clinical trial. medRxiv. doi: 10.1101/2020.03.22.20040758

CHORIN E.; WADHWANI L.; MAGNANI S.; DAI M.; SHULMAN E.; ROUTHIER C.N.; et al. QT Interval Prolongation and Torsade De Pointes in Patients with COVID-19 treated with Hydroxychloroquine/Azithromycin. Heart Rhythm. 2020 May 11. S15475271(20)30435-5. doi: 10.1016/j.hrthm.2020.05.014

COLLIN J.; QUEEN R.; ZERTI D.; DORGAU B.; GEORGIOU M.; DJIDROVSKI I.; et al. Co-expression of SARS-CoV-2 entry genes in the superficial adult human 
conjunctival, limbal and corneal epithelium suggests an additional route of entry via the ocular surface. Ocul Surf [Internet]. 2020 Jun;(May). Available from: https://linkinghub.elsevier.com/retrieve/pii/S1542012420300975. doi: 10.1016/j.jtos.2020.05.013

CONNORS J.M.; LEVY J.H. COVID-19 and its implications for thrombosis and anticoagulation. Blood. 2020;135(23):2033-2040. doi: 10.1182/blood.2020006000

DENG X.; HACKBART M.; METTELMAN R.C.; O'BRIEN A.; MIELECH A.M.; YI G.; et al. Coronavirus nonstructural protein 15 mediates evasion of dsRNA sensors and limits apoptosis in macrophages. Proc Natl Acad Sci USA. 2017;114(21):E4251-60. doi: 10.1073/pnas.1618310114

DUMAS-MALLET E.; BUTTON K.S.; BORAUD T.; GONON F.; MUNAFÒ M.R. LoW statistical power in biomedical science: A review of three human research domains. $\mathbf{R}$ Soc Open Sci. 2017;4(2). doi: 10.1098/rsos.160254

Fact sheet for health care providers Emergency Use Authorization (EUA) of remdesivir (GS-5734 ${ }^{\mathrm{TM}}$ ) [Internet]. US Food and Drug Administration; 2020 - [cited 2020 Aug 10]. Available from: https://www.fda.gov/media/137566/download.

Folha informativa - COVID-19 (doença causada pelo novo coronavírus) [Internet]. Brasília: Organização Pan-Americana da Saúde; 2020 - [citado em 2020 Jul 27]. Disponível em: https://www.paho.org/bra/index.php?option=com_content\&view=article\&id=6101:covi d19\&Itemid=875

FRIEMAN M.; BARIC R. Mechanisms of Severe Acute Respiratory Syndrome Pathogenesis and Innate Immunomodulation. Microbiol Mol Biol Rev. 2008;72(4):672-85. doi: 10.1128/MMBR.00015-08

FRIEMAN M.; YOUNT B.; HEISE M.; KOPECKY-BROMBERG S.A.; PALESE P.; BARIC R.S. Severe Acute Respiratory Syndrome Coronavirus ORF6 Antagonizes 
STAT1 Function by Sequestering Nuclear Import Factors on the Rough Endoplasmic Reticulum/Golgi Membrane. J Virol. 2007;81(18):9812-24. doi: 10.1128/JVI.01012-07

GAO J.; TIAN Z.; YANG X. Breakthrough: Chloroquine phosphate has shown apparent efficacy in treatment of COVID-19 associated pneumonia in clinical studies. Biosci Trends. 2020;14(1):72-3. doi: 10.5582/bst.2020.01047

GAUTRET P.; LAGIER J-C.; PAROLA P.; HOANG V.T.; MEDDEDB L.; MAILHE M.; et al. Clinical and microbiological effect of a combination of hydroxychloroquine and azithromycin in 80 COVID-19 patients with at least a six-day follow up: A pilot observational study. Travel Med. Infect. Dis. March-April 2020. doi: 10.1016/j.tmaid.2020.101663

GAUTRET P.; LAGIER J-C.; PAROLA P.; HOANG V.T.; MADDEB L.; MAILHE M.; et al. Hydroxychloroquine and azithromycin as a treatment of COVID-19: results of an open-label non-randomized clinical trial. Int $\mathbf{J}$ Antimicrob Agents [Internet]. doi: 10.1016/j.jjantimicag.2020.105949

GHEZZI S.; COOPER L.; RUBIO A.; PAGANI I.; CAPOBIANCHI M.R.; IPPOLITO G.; et al. Heparin prevents Zika virus induced-cytopathic effects in human neural progenitor cells. Antiviral Res [Internet]. 2017;140:13-7. doi: 10.1016/j.antiviral.2016.12.023

GOLDMAN J.D.; LYE D.C.B.; HUI D.S.; MARKS K.M.; BRUNO R.; MONTEJANO R.; et al. Remdesivir for 5 or 10 Days in Patients with Severe Covid-19. N Engl J Med [Internet]. 2020 May 27;NEJMoa2015301. Available from: http://www.ncbi.nlm.nih.gov/pubmed/32459919. doi: 10.1056/NEJMoa2015301

GUAN W.J.; NI Z.Y.; HU Y.; LIANG W.H.; OU C.Q.; HE J.X.; et al. Clinical Characteristics of Coronavirus Disease 2019 in China. N Engl J Med. 2020;382(18):1708-1720. doi: 10.1056/NEJMoa2002032

GUPTA S.; TANDON V.R.; SHARMA S.D.; GUPTA R.K. Nitazoxanide: Broad Spectrum Anti-Protozoal. JK Science. 2006;8(1):60-1. 
HARROP H.A.; RIDER C.C. Heparin and its derivatives bind to HIV-1 recombinant envelope glycoproteins, rather than to recombinant HIV-1 receptor, CD4. Glycobiology. 1998;8(2):131-7. doi: 10.1093/glycob/8.2.131

HILLEN H.S.; KOBIC G.; FARNUNG L.; DIENEMANN C.; TEGUNOV D.; CRAMER P. Structure of replicating SARS-CoV-2 polymerase. Nature [Internet]. 2020 May $21 ; 2020.04 .27 .063180$. doi: 10.1038/s41586-020-2368-8

HORBY P.; LIM W.S.; EMBERSON J.R.; MAFHAM M.; BELL J.L.; LINSELL L.; et al. Dexamethasone in Hospitalized Patients with Covid-19 - Preliminary Report. N Engl J Med [Internet]. 2020;1-11. Available from: http://www.ncbi.nlm.nih.gov/pubmed/32678530. doi: 10.1056/NEJMoa2021436

ISON M.G.; WOLF C.; BOUCHER H.W. Emergency Use Authorization of Remdesivir. JAMA [Internet]. 2020 May 14. doi: 10.1001/jama.2020.8863

JASENOSKY L.D.; CADENA C.; MIRE C.E.; BORISEVICH V.; HARIDAS V.; RANJBAR S.; et al. The FDA-Approved Oral Drug Nitazoxanide Amplifies Host Antiviral Responses and Inhibits Ebola Virus. iScience [Internet]. 2019;19:1279-90. doi: 10.1016/j.isci.2019.07.003

JORGENSEN S.C.; KEBRIAEI R.; DRESSER L.D. Remdesivir: Review of pharmacology, pre-clinical data and emerging clinical experience for COVID-19. Pharmacotherapy [Internet]. 2020 May 23;phar.2429. Available from: http://www.ncbi.nlm.nih.gov/pubmed/32446287. doi: 10.1002/phar.2429

KORBA B.E.; MONTERO A.B.; FARRAR K.; GAYE K.; MUKERJEE S.; AYERS M.S.; et al. Nitazoxanide, tizoxanide and other thiazolides are potent inhibitors of hepatitis $B$ virus and hepatitis C virus replication. Antiviral Res. 2008;77(1):56-63. doi: 10.1016/j.antiviral.2007.08.005

LIAO Y.; LIANG W.; CHEN F.; HSU J.; YANG J.; CHANG M. IL-19 Induces Production of IL- 6 and TNF- $\alpha$ and Results in Cell Apoptosis Through TNF- $\alpha$. The Journal of Immunology. 2002;169(8):4288-4297. doi: 10.4049/jimmunol.169.8.4288 
LIU J.; CAO R.; XU M.; WANG X.; ZHANG H.; HU H.; et al. Hydroxychloroquine, a less toxic derivative of chloroquine, is effective in inhibiting SARS-CoV-2 infection in vitro. Cell Discov [Internet]. 2020;6(1):6-9. doi: 10.1038/s41421-020-0156-0

LOKMAN S.M.; RASHEDUZZAMAN M.D.; SALAUDDIN A.; BARUA R.; TANZINA A.Y.; RUMO M.H.; et al. Exploring the genomic and proteomic variations of SARSCoV-2 spike glycoprotein: A computational biology approach. Infect Genet Evol [Internet]. 2020 Jun;104389. doi: 10.1016/j.meegid.2020.104389

MAGAGNOLI J.; NARENDRAN S.; PEREIRA F.; CUMMINGS T.; HARDIN J.W.; SUTTON S.S.; et al. Outcomes of hydroxychloroquine usage in United States veterans hospitalized with Covid-19. medRxiv. doi: 10.1101/2020.04.16.20065920

MAHÉVAS M.; TRAN V-T.; ROUMIER M.; CHABROL A.; PAULE R.; GUILLAUD C.; et al. Clinical efficacy of hydroxychloroquine in patients with covid-19 pneumonia who require oxygen: observational comparative study using routine care data. Bmj. doi: 10.1136/bmj.m1844

MALIK, Y.A. Properties of Coronavirus and SARS-CoV-2. Malays J Pathol [Internet]. 2020 Apr;42(1):3-11. Available from: http://www.ncbi.nlm.nih.gov/pubmed/32342926

MATHIAN A.; MAHEVAS M.; ROHMER J.; ROUMIER M.; COHEN-AUBART F.; AMADOR-BORRERO B.; et al. Clinical course of coronavirus disease 2019 (COVID19 ) in a series of 17 patients with systemic lupus erythematosus under long-term treatment with hydroxychloroquine. Ann Rheum Dis. 2020;79(6):2019-21. doi: 10.1136/annrheumdis-2020-217566

MENZEL M.; AKBARSHAHI H.; BJERMER L.; ULLER L. Azithromycin induces antiviral effects in cultured bronchial epithelial cells from COPD patients. Sci Rep. 2016;6:28698. Published 2016 Jun 28. doi: 10.1038/srep28698

MERAD M.; MARTIN J.C. Pathological inflammation in patients with COVID-19: a key role for monocytes and macrophages. Nat Rev Immunol [Internet]. 2020;20(6):35562. doi: 10.1038/s41577-020-0331-4 
MULLARD A. Could pharma open its drug freezers? Nat Rev Drug Discov [Internet]. 2011 Jun [cited 2020 Apr 6];10(6):399-400. Available from: http://www.ncbi.nlm.nih.gov/pubmed/21629278. doi: 10.1038/nrd3473

MYCROFT-WEST C.; SU D.; PAGANI I.; RUDD T.; ELLI S.; GUIMOND S.; et al. Heparin inhibits cellular invasion by SARS-CoV-2: structural dependence of the interaction of the surface protein (spike) S1 receptor binding domain with heparin. bioRxiv. 2020. doi: 10.1101/2020.04.28.066761

NEGRI E.; PILOTO B.; MORINAGA L.; JARDIM C.; LAMY S.; FERREIRA M.; et al. Heparin therapy improving hypoxia in COVID-19 patients - a case series. medRxiv. 2020. doi: $10.1101 / 2020.04 .15 .20067017$

Painel Coronavírus [Internet]. Brasília: Ministério da Saúde; 2020 - [citado em 2020 Ago 31]. Disponível em: https://covid.saude.gov.br/

RANGANATHAN P.; PRAMESH C.; AGGARWAL R. Common pitfalls in statistical analysis: Intention-to-treat versus per-protocol analysis. Perspect Clin Res. 2016;7(3):144. doi: 10.4103/2229-3485.184823

ROLAIN J.M.; COLSON P.; RAOULT D. Recycling of chloroquine and its hydroxyl analogue to face bacterial, fungal and viral infections in the 21 st century. Int $\mathbf{J}$ Antimicrob Agents. 2007;30(4):297-308. doi: 10.1016/j.jjantimicag.2007.05.015

ROSSIGNOL J.F. Nitazoxanide: A first-in-class broad-spectrum antiviral agent. Antiviral Res. 2014;110:94-103. doi: 10.1016/j.antiviral.2014.07.014

RUSNATI M.; COLTRINI D.; OREST P.; ZOPPETTI G.; ALBINI A.; NOONAN D.; et al. Interaction of HIV-1 Tat protein with heparin. Role of the backbone structure, sulfation, and size. J Biol Chem. 1997;272(17):11313-20. doi: 10.1074/jbc.272.17.11313

SHI C.; WANG C.; WANG H.; YANG C.; CAI F.; ZENG F.; et al. The potential of low molecular weight heparin to mitigate cytokine storm in severe COVID-19 patients: a retrospective clinical study. medRxiv. 2020. doi: 10.1101/2020.03.28.20046144 
SIEGEL D.; HUI H.C.; DOERFFLER E.; CLARKE M.O.; CHUN K.; CHANG L.; et al. Discovery and Synthesis of a Phosphoramidate Prodrug of a Pyrrolo[2,1- $f$ ][triazin-4amino] Adenine C -Nucleoside (GS-5734) for the Treatment of Ebola and Emerging Viruses. J Med Chem [Internet]. 2017 Mar 9;60(5):1648-61. Available from: http://www.ncbi.nlm.nih.gov/pubmed/28124907. doi: 10.1021/acs.jmedchem.6b01594

SKIDMORE M.A.; KAJASTE-RUDNITSKI A.; WELLS N.M.; GUIMOND S.E.; RUDD T.R.; YATES E.A.; et al. Inhibition of influenza H5N1 invasion by modified heparin derivatives. Medchemcomm [Internet]. 2015;6(4):640-6. doi: 10.1039/c4md00516c

SUN W.; HEB W.; ROMERO M.C.; KOUZNETSOVA J.; TAWA G.; XU M.; et al. Synergistic drug combination effectively blocks Ebola virus infection. Antiviral research. January 2017, volume 137, pages 165-172. doi: 10.1016/j.antiviral.2016.11.017

TANG N.; BAI H.; CHEN X.; GONG J.; LI D.; SUN Z. Anticoagulant treatment is associated with decreased mortality in severe coronavirus disease 2019 patients with coagulopathy. J ThrombHaemost. 2020;18(5):1094-1099. doi: 10.1111/jth.14817

TANG W.; CAO Z.; HAN M.; WANG Z.; CHEN J.; SUN W.; et al. Hydroxychloroquine in patients with mainly mild to moderate coronavirus disease 2019: open label, randomised controlled trial. Bmj. 2020;(April):m1849. doi: 10.1136/bmj.m1849

TOTURA A.L.; BAVARI S. Broad-spectrum coronavirus antiviral drug discovery. Expert Opin Drug Discov [Internet]. 2019;14(4):397-412. doi: $10.1080 / 17460441.2019 .1581171$

VICENZI E.; CANDUCCI F.; PINNA D.; MANCINI N.; CARLETTI S.; LAZZARIN A.; et al. Coronaviridae and SARS-associated. Emerg Infect Dis. 2004;10(3). doi: 10.3201/eid1003.030683

WADMAN M.; COUZIN-FRANKEL J.; KAISER J.; MATACIC C. A rampage through the body. Science. 2020;368(6489):356-360. doi: 10.1126/science.368.6489.356 
WANG M.; CAO R.; ZHANG L.; YANG X.; LIU J.; XU M.; et al. Remdesivir and chloroquine effectively inhibit the recently emerged novel coronavirus (2019-nCoV) in vitro. Cell Res. 2020;30(3):269-71. doi: 10.1038/s41422-020-0282-0

WANG Y.; ZHANG D.; DU G.; DU R.; ZHAO J.; JIN Y.; et al. Remdesivir in adults with severe COVID-19: a randomised, double-blind, placebo-controlled, multicentre trial. Lancet [Internet]. 2020 May;395(10236):1569-78. Available from: https://linkinghub.elsevier.com/retrieve/pii/S0140673620310229. doi: 10.1016/S01406736(20)31022-9

WHO coronavirus disease (COVID-19) dashboard [Internet]. Geneva: World Health Organization; 2020 - [cited 2020 Aug 31]. Available from: https://covid19.who.int

WIERSINGA W.J.; RHODES A.; CHENG A.C.; PEACOCK S.J.; PRESCOTT H.C. Pathophysiology, Transmission, Diagnosis, and Treatment of Coronavirus Disease 2019 (COVID-19): A Review. Jama [Internet]. 2020;2019:1-13. Available from: http://www.ncbi.nlm.nih.gov/pubmed/32648899. doi: 10.1001/jama.2020.12839

WUDUNN D.; SPEAR P.G. Initial interaction of herpes simplex virus with cells is binding to heparan sulfate. J Virol. 1989;63(1):52-8.

WU Y-C.; CHEN C-S.; CHAN Y-J. The outbreak of COVID-19: An overview. Journal of the Chinese Medical Association. March 2020 - Volume 83 - Issue 3 - p 217-220. doi: 10.1097/JCMA.0000000000000270

YANG X.; YANG Q.; WANG Y.; WU Y.; XU J.; YU Y.; et al. Thrombocytopenia and its association with mortality in patients with COVID-19. $\boldsymbol{J}$ ThrombHaemost. 2020;18(6):1469-1472. doi: 10.1111/jth.14848

YAO X.; YE F.; ZHANG M.; CUI C.; HUANG B.; NIU P.; et al. In Vitro Antiviral Activity and Projection of Optimized Dosing Design of Hydroxychloroquine for the Treatment of Severe Acute Respiratory Syndrome Coronavirus 2 (SARS-CoV-2). Clin Infect Dis. 2020;(Xx):1-8. doi: 10.1093/cid/ciaa237 
ZHANG L.; YAN X.; FAN Q.; LIU H.; LIU X.; LIU Z.; et al. D-dimer levels on admission to predict in-hospital mortality in patients with Covid-19. J ThrombHaemost. 2020;18(6):1324-1329. doi: 10.1111/jth.14859

ZHOU D.; DAI S.M.; TONG Q. COVID-19: a recommendation to examine the effect of hydroxychloroquine in preventing infection and progression. J Antimicrob Chemother. 2020; (February):4-7. doi: 10.1093/jac/dkaa114

Enviado: Setembro, 2020.

Aprovado: Outubro, 2020. 